\title{
INDICES DE MORBILIDAD E INCIDENCIA DE ENFERMEDADES ENTRE LOS ESCLAVOS EN LA \\ HABANA, 1580-1699
}

\section{Alejandro de la Fuente García}

\section{Introducción}

El estudio de las sociedades esclavistas americanas ha recibido, en los últimos años, una creciente atención por parte de numerosos especialistas de todo el orbe; sociólogos, historiadores, juristas y estudiosos de disciplinas afines han buscado en el pasado las raíces de múltiples problemas sociales contemporáneos, propios de aquellos países en que existió la nefasta institución.

Desde luego, también en Cuba el tema ha sido objeto de atención aunque subsisten inexplorados no pocos aspectos de interés y largos períodos evolutivos de la institución que no han sido suficientemente estudiados, destacándose una etapa inicial —que cubre, aproximadamente, los tres primeros siglos de historia colonial, hasta la toma de La Habana por los ingleses (1762) - en la que nuestros conocimientos sobre el tema resultan sumamente incompletos.

En medio de ese interés, los estudios acerca de la mortalidad y morbilidad esclavas han rendido ya, en otros países, resultados investigativos de indudable valor (1). En Cuba, en cambio, el tema apenas ha sido tratado; como señala Oscar Zanetti (2), «un tema de indiscutible significación social como el de las enfermedades y la salud apenas ha sido abordado (...) 
resultando muy escasos los trabajos dedicados al conocimiento histórico de la incidencia de algunas enfermedades y, en particular, de las epidemias, de tanta importancia en la vida social de la colonia».

El presente trabajo estudia las principales enfermedades detectadas en una muestra de 4.446 esclavos existentes en La Habana a fines del siglo XVI y a lo largo de todo el XVII (1580-1699) (3). Dada la inexistencia de registros sanitarios o series análogas que permitan evaluar el fenómeno de forma global, los datos fueron extraídos a partir de las escrituras individuales de compraventa de esclavos $\mathrm{u}$ otros documentos similares (inventarios, tasaciones) que aparecen inmersos en el complejo paisaje jurídico contractual de los Protocolos Notariales de la época.

Claro está que ello supone la necesidad de revisar grandes volúmenes de documentación para extraer la información deseada; una dificultad adicional, mencionada por diferentes autores (4), se refiere a la clasificación de las dolencias, dado que a veces un mismo término designaba - por presentar síntomas similares- enfermedades muy diferentes. Además, como señala Grande Esteban (5), en los siglos XVI y XVII «la terminología de los físicos, cirujanos, empíricos, etc., era caótica, pues no existía ningún acuerdo entre los distintos profesionales de la medicina, ni tampoco entre los humanistas».

La mención de enfermedades aparece en las cartas de compraventa junto a otros indicadores destinados a describir al esclavo, bien objeto de la operación, y su importancia estaba dada por el hecho de que los mismos fungían como elementos modificadores del precio. Aunque el vendedor estaba interesado en ocultar a toda costa los defectos y enfermedades del esclavo y declararía, de hecho, sólo aquéllos que por su sintomatología no era posible ocultar, el comprador revisaba cuidadosamente la «mercancía», de ahí que la confiabilidad de esta documentación esté garantizada, de inicio, por los intereses en pugna. Además, en caso de adquirir un esclavo con vicios o defectos ocultos, el comprador tenía el derecho de reclamar legalmente la devolución del precio.

Dado que, según queda dicho, resulta sumamente difícil identificar y clasificar las enfermedades registradas, autores precedentes han optado por agruparlas de acuerdo con los síntomas que provocaban en diversos sistemas del cuerpo y no con la etiología de las mismas. Sin embargo, no resulta del todo imposible identificarlas adecuadamente, ya que mediante el estudio de los textos médicos de la época es posible lograr una idea bastante aproximada acerca del contenido y alcance de cada denominación.

Por ello, siempre que fue posible, se intentó agruparlas de acuerdo 
con criterios más modernos, aunque en algunos casos la vaguedad de los términos utilizados - «enfermo», "con calenturas», (fiebre)— hacen desde todo punto de vista imposible una clasificación.

Los datos fueron agrupados en tres categorías, de acuerdo con las características de los esclavos tabulados; los bozales son africanos recién introducidos en el país, es decir, son aquéllos que integran los cargamentos y que son vendidos por primera vez en tierras cubanas; aunque algunos de estos esclavos eran importados de otras colonias americanas, que servían como depósitos esclavistas continentales, esta categoría permite conocer, en general, los elementos patógenos aportados por los africanos a la Isla.

Por oposición a la anterior, los ladinos eran aquéllos que habían permanecido determinado período de tiempo en el país y mostraban, por tanto, cierto nivel de integración cultural y de adaptación al nuevo medio. A diferencia de los bozales, en este grupo se incluían algunos esclavos criollos, nacidos en la Isla.

Los azucareros, por último, fueron agrupados, como su denominación indica, a partir de un criterio de tipo ocupacional; aunque los documentos de la época rara vez consignan la ocupación del esclavo - de ahí que sea imposible establecer comparaciones con otras categorías análogas- el grupo merece un tratamiento aparte, por hallarse vinculado a uno de los renglones productivos fundamentales de la época. Además, según se verá más adelante, es una clasificación de interés a los efectos del trabajo.

\section{Análisis de los resultados y discusión}

En el total de la muestra $(n=4.446)$ se registran solamente 333 enfermos, para un índice general de morbilidad del 7.5\%. Entre los hombres el índice es algo mayor (8.6\%) que entre las mujeres (5.7\%), característica que se observa entre los bozales (14.4\% y 10.1\%) y ladinos (3.6\% y $3.3 \%$ ); en el caso de los azucareros no se reportan mujeres y no es posible, en consecuencia, establecer tal comparación.

Las anteriores cifras denotan igualmente que la proporción de esclavos enfermos en uno $\mathrm{u}$ otro grupo variaba considerablemente; la tabla 1 presenta la distribución de las clases de enfermedades reportadas en las diferentes categorías, mostrando igualmente diferencias importantes: 
Tabla 1. Clases de enfermedades por categorías; distribución relativa.

\begin{tabular}{lccc}
\hline \multicolumn{1}{c}{ Clases de enfermedades } & $\begin{array}{c}\text { Bozales } \\
(n=91)\end{array}$ & $\begin{array}{c}\text { Ladinos } \\
(n=189)\end{array}$ & $\begin{array}{c}\text { Azucareros } \\
(n=53)\end{array}$ \\
\hline Enf. del sistema digestivo & 24.2 & 1.6 & 1.9 \\
Enf. del sistema respiratorio & - & 1.1 & 1.9 \\
Tuberculosis & - & 0.5 & 1.9 \\
Otras enfermedades bacterianas & - & 0.5 & - \\
Enf. venéreas & 6.6 & 3.7 & 3.8 \\
Enf. órganos genitales femeninos & - & 1.6 & - \\
Enf. del sistema nervioso & - & 1.1 & - \\
Trastornos mentales & - & 51.8 & 3.8 \\
Enf. del sistema circulatorio & 2.2 & 2.6 & 3.8 \\
Enf. cardiovasculares & 1.1 & - & - \\
Trastornos de la vista & 3.3 & 6.9 & 11.3 \\
Enf. del oído & 2.2 & - & - \\
Enf. de la piel y tejido subcutáneo & 3.3 & 9.0 & 17.0 \\
Enf. del sistema musculoesquelético & 5.5 & 12.2 & 39.6 \\
Fracturas & - & 0.5 & 3.8 \\
Deficiencias nutricionales & 42.8 & $\overline{-}$ & $-\overline{-}$ \\
Otras enfermedades & 7.7 & 6.9 & 11.2 \\
Indices de morbilidad (en \%) & 3.5 & 12.6 & 16.4 \\
\hline
\end{tabular}

Fuente: Archivo Nacional de Cuba (ANC). Protocolos Notariales de La Habana.

Entre los bozales, las enfermedades más comunes estaban vinculadas a problemas alimentarios y digestivos provocados fundamentalmente por las condiciones sanitarias en que se verificaba el viaje atlántico, consideradas como muy nocivas por el médico Francisco Barrera y Domingo (6) a fines del siglo XVIII. Las dolencias más frecuentemente mencionadas eran las cámaras y cursos, denominaciones que designaban desde la disentería hasta el síndorme diarreico agudo (figura 1).

La disentería era una enfermedad común en la época y es probable que muchos esclavos la contrajeran en los depósitos africanos, agravándose durante el viaje (7). El holandés Willem Pies, que trabajó como médico en Brasil entre 1637 y 1645, la describía como «unos flujos acompañados de sangre y fiebre» (8), mientras Farfán, en pleno siglo XVI, la consideraba una enfermedad letal, especialmente si provocaba "calenturas y mala gana de comen, es decir, fiebre e inapetencia. Este último, además, la distinguía de otras dolencias análogas al señalar que su intención era 
tratar de «las cámaras de sangre, que los griegos llaman disentería (...) y no de otras cámaras que hay, por no ser tan peligrosas» (9).

Entre las dolencias que provocaban trastornos nutricionales en los bozales se menciona la caquexia africana, conocida en las colonias hispanas como mal de comer tierra, en las inglesas como dirt eating (10) y llamada mal d'estomac (11) entre los franceses, que la reputaban originaria de Africa y la consideraban una enfermedad de etiología moral que provocaba serias deficiencias nutricionales (12). El padre Labat (13) se refiere a ella como causada por una "melancolía negra" y en el siglo XIX Honorato Bernard de Chateausalins (14), que se desempeñó como médico de esclavos en los ingenios de Cuba, la caracterizaba por su «total abandono a la pesadumbre y la desesperación, por la pérdida de apetito y continuo dolor de estómago (...) es una verdadera consunción provocada por falta de nutrición». La enfermedad, causada al parecer por un gusano nematodo, provocaba una anemia intensa, fiebre y serios trastornos digestivos, cuyo síntoma fundamental era la ingestión de tierra u otras sustancias sin valor nutritivo.

Otra enfermedad relativamente frecuente entre los bozales y entre los esclavos en general eran las bubas (figura 1), denominación que al decir de Moreno Fraginals (15) designaba un «vastísimo complejo de enfermedades, no bien diagnosticadas, cuyo síntoma exterior era la aparición de llagas, granos o ganglios inflamados».

La vaguedad del término es confirmada por fuentes y autores diversos que coinciden en el hecho de que el mismo comprendía dolencias muy diferentes, como el pian, la sífilis y el linfogranuloma venéreo (16). Todavía en el presente siglo innumerables afecciones de la piel —pústulas, llagas y empeines- eran designadas como «bubas» (17); en un estudio realizado en Jamaica en 1932 no se pudo determinar en el ocho por ciento de los casos cuándo las afecciones epidérmicas eran causadas por las bubas o la sífilis (18) y aún en la actualidad hay quienes identifican ambas enfermedades (19).

En los siglos XVI y XVII la confusión era, desde luego, mucho mayor y la creencia popular es que existían más de sesenta tipos de bubas que cubrían dolencias tan diversas como la gota, el asma, jaquecas y otros males (20); los médicos, sin embargo, utilizaban el término para designar, en general, las enfermedades de origen venéreo (21), aunque la sífilis era también llamada en la época «humor gálico», «morbo gálico»o «mal francés».

Claro está que muchas de las enfermedades consideradas por los médicos de la época como de origen venéreo tenían una etiología muy 
diferente, de manera que resulta imposible determinar con precisión las dolencias incluidas bajo la denominación de bubas; la gráfica descripción que Farfán (22) hace de la enfermedad, cuya curación considera "parte muy principal de la medicina», es prueba de ello:

«Son tantos y tan diversos los accidentes de esta enfermedad, que a unos aflije con una manera de sarna y leprilla en algunas partes de su cuerpo y a otros en todo él. A unos aflije con unos como empeines y postillas en la cabeza y en el rostro, a otros aflije pelándoles las cejas y las pestanas, la cabeza y la barba. A unos aflije con graves dolores de junturas y de cabeza, a otros con corrupción en los huesos de ella y de las espinillas; y finalmente a otros con llagas en las partes vergonzosas y con encordios y con continua purgación de materias por la vía de la orina».

Entre los bozales eran también relativamente comunes otras enfermedades como la filariasis, afecciones epidérmicas diversas y la viruela (23); en un cargamento llegado a la ciudad en 1628 se alegaba que venían algunos esclavos enfermos "así de viruelas como de otras enfermedades» (24) y en 1668 las autoridades habaneras señalaban la necesidad que había de esclavos "particularmente por la enfermedad que Dios Nuestro Señor ha servido de enviar de viruelas y otros achaques en que han muerto más de seiscientos negros» (25).

La viruela fue una de las enfermedades que mayor incidencia tuvo en la población aborigen insular, y en el siglo XVI ya se la distinguía del sarampión, que era considerado como una variante de aquélla. Farfán (26) las describía, por ejemplo, diciendo que existían dos «maneras» de viruelas, «unas altas y gruesas» consideradas letales y unas «bajas y menudas (...) las que llaman sarampión». Según diversos testimonios de la época, ambas dolencias tuvieron una altísima incidencia entre los habitantes de la Isla, tanto libres como esclavos (27).

Entre los ladinos, la enfermedad más frecuentemente reportada es el síndrome de dependencia alcohólica (figura 1), incluida entre los trastornos mentales (tabla 1). En realidad, los documentos de la época no permiten conocer la gravedad de la dolencia y se limitan a consignar, en el contrato de compraventa, el hábito de ingerir licores como un defecto del esclavo. En 1604, por ejemplo, se vende una esclava "por puta (sic) y borracha» (28) y en 1694 el comprador de la negra Juana criolla promovió un pleito "por haberse dèscubierto en su poder la falta de borracha» (29).

Aunque los dos ejemplos anteriores se refieren a mujeres, el alcoholismo 


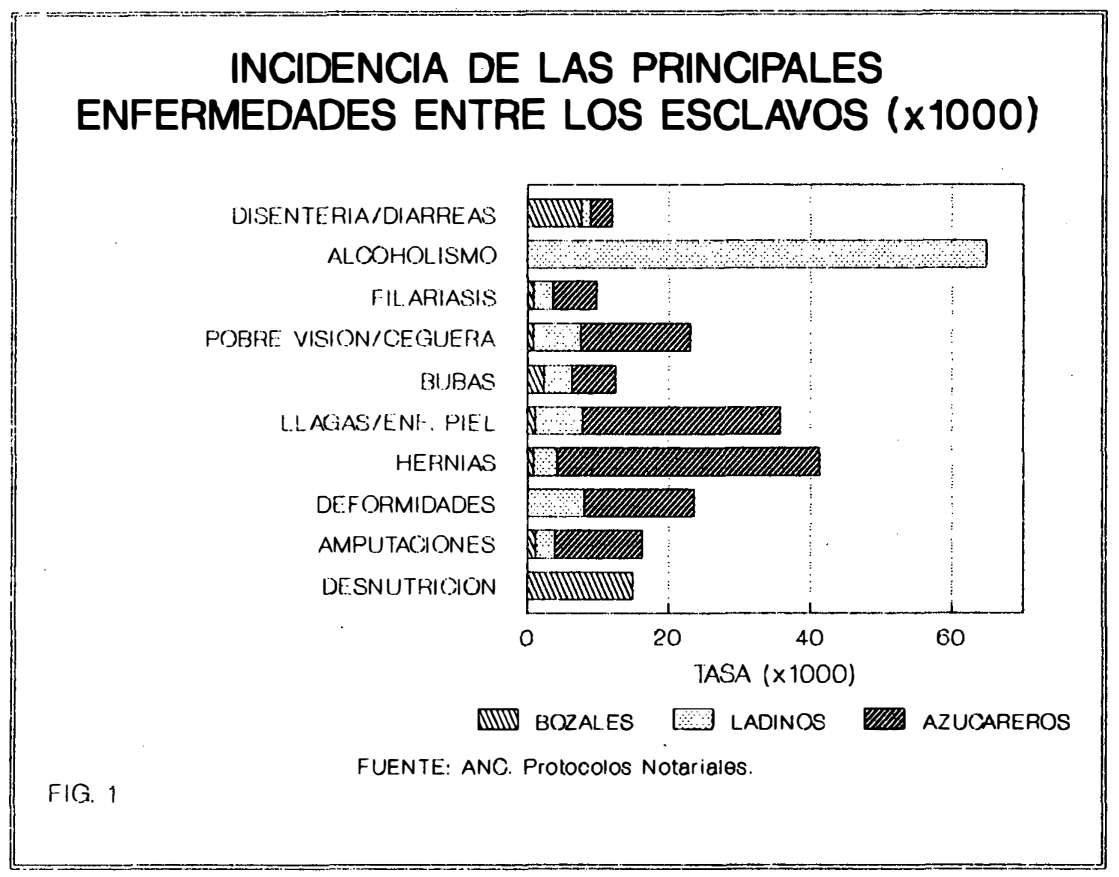

fue, fundamentalmente, una dolencia masculina, siendo 1.8 veces más frecuente entre los hombres que entre las mujeres. El acceso al consumo de licores era facilitado, en La Habana, por la vinculación de los esclavos a la pujante economía de servicios de la ciudad, desarrollada en virtud de su condición de puerto escala de todas las flotas y armadas imperiales y de plaza comercial de nivel continental. Téngase en cuenta que hacia 1570 existían más de cincuenta tabernas en la villa y que un siglo después, en 1673, se reportan unas ochenta (30).

Entre los trastornos mentales se incluyen igualmente algunas dolencias de menor incidencia, como los "dementados» y "espiritados», denominaciones que resulta difícil precisar con exactitud; frecuentemente, en los contratos se hacía constar que el esclavo gozaba de buena salud mental, al asegurar que el mismo no era "endemoniado» (31).

Entre los azucareros hay una clara prevalencia de las enfermedades que afectan al sistema musculoesquelético, en especial las hernias, defor- 
midades y defectos de las extremidades y amputaciones; son también algo frecuentes las fracturas (figura 1).

Los esclavos encargados de moler la caña - los llamados moledoresestaban constantemente expuestos al riesgo de perder un dedo, la mano o aun el brazo debido a las características del trabajo que realizaban. Con el objetivo de extraerle todo el jugo, la caña era pasada dos veces por el trapiche; el esclavo encargado de introducirla entre las mazas por segunda vez tenía que acercar mucho la mano, debido a que la misma carecía de la consistencia necesaria para hacerlo desde lejos, como ocurría en el primer pase, de ahí que los accidentes ocurrieran con relativa frecuencia (32).

Los esclavos azucareros fueron igualmente víctimas de numerosas dolencias de la piel, como empeines, fístulas - «llagas callosas que siempre echan de sí materia» (33) - y apostemas, dolencia que, de acuerdo con la patología humoral de la época, Sorapán de Rieros (34) califica como una «hichazón, hecha de humores que se juntan en alguna parte de nuestro cuerpo, donde se suelen corromper». Se reportan también algunos esclavos con trastornos de la vista, los cuales eran, según Pies (35), muy comunes en la época, especialmente el conocido como nubes en los ojos producido, al decir de Farfán, por un "continuo corrimiento de humores» (36).

La salud y el estado físico de los esclavos, en sentido general, tenían, desde luego, una notable influencia en el precio. En un cargamento de esclavos introducido en la ciudad en 1692, por ejemplo, los niños enfermos se deprecian un $49.4 \%$ y los adultos un $60.5 \%$ en relación con los sanos. Entre los ladinos el proceso de desvalorización parece ser menos agudo, pero significativo en cualquier forma (figura 2).

Los precios pueden ser utilizados igualmente como un indicador acerca de la gravedad que el mercado de brazos de la época le atribuía a una u otra enfermedad. La figura 2 muestra que aquellas dolencias que limitaban de forma permanente la capacidad productiva del esclavo eran las que más incidían en el precio, deprimiéndolo notablemente. Esta tendencia es claramente visible en el caso de amputaciones, los trastornos de la vista y la epilepsia - conocida en la época como mal de corazón o gota coralque provocan una depreciación de alrededor de un 30\% en relación con los sanos.

Otras dolencias, en cambio, era percibidas de manera diferente; el síndrome de dependencia alcohólica, por ejemplo, no era considerado problema de salud, sino un defecto del esclavo que no limitaba su precio en el mercado, lo cual indica que el calificativo de «borracho", utilizado 


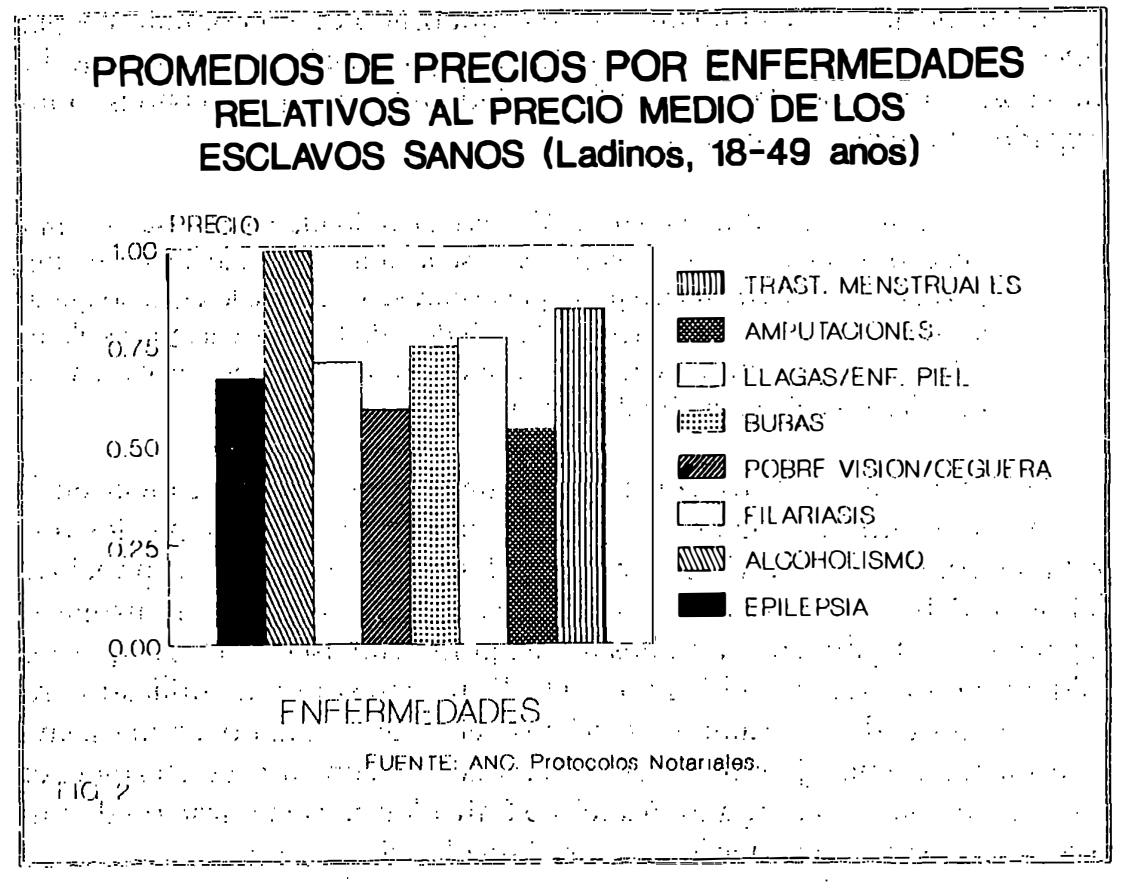

en los contratos de venta, no designaba en realidad un estado patológico, sino un desajuste de tipo social.

Otró tanto ocurre en el cáso de los trastornos menstruales registrados, entre las esclavas, cuya incidencia en el preció erá prácticamente nulá. Cồno esós trastón ó eran fácilmente ocultables, es probabile que su incidencia fueră mayor que lo detectado por nosotros, además, los autores de la época coinciden en que era un mal muy exténdido (37) y ló átribuían a la "constitución de la sangré, "serer muy gruesá y muy flemáticai (38). Junto a éstos, se reporta un casò con proläpso genital - -enfermedad observada entre las esclavas de otras zonas"del continente (39)-considerado como una consecuencia de los trastornos menstruales y de fáctores climáticos y: dietéticos (40).

El ocultamiento por parte del vendedor de los defectos del esclavo provocaba un sinnúmero de pleitos en los que el comprador denunciaba haberlo recibido sin la aclaración de las enfermedades «que tenía ocultas». En 1671 (41), por ejemplo, el adquirente del negro Gabriel, criollo dẻ 
Veracruz, declara que el mismo estaba «quebrado de un compañón» (42) (hernia escrotal) y con calenturas (fiebre) que, según el parecer de los médicos, era provocada por la enfermedad de humor gálico (sífilis); interrogado, el esclavo declaró que:

«...en la ciudad de la Nueva Veracruz (...) donde nació y se crió muchacho se quebró de un compañón y se le empezó a hinchar y [su ama] (...) llamó a un cirujano (...) para que lo curase y aunque lo curó no quedó sano y después de algún tiempo, habiéndole dado unas calenturas, llamó (...) su ama a Ventura de Gracia para que lo curase y este declarante le manifestó la dicha quebradura y dijo que no era nada..."

Dado que los esclavos constituían una valiosísima mercancía en la época -y su muerte una pérdida económica de consideración- los propietarios contrataban servicios especializados para su curación. A principios del siglo XVII Juan Maldonado, uno de los primeros azucareros insulares, pagaba ochenta ducados anuales al cirujano Francisco Salvador para el cuidado de los negros del ingenio (43). El mecanismo más utilizado era, sin embargo, el de contratar los servicios del médico cuando algún esclavo enfermaba. Como ejemplo, merece citarse un contrato concertado en 1640 con el maestro cirujano Francisco Salvador para la curación de una esclava enferma, de acuerdo con las cláusulas siguientes:

a) El propietario le entregaba una esclava «enferma de un apostema junto a la cadera izquierda arrimada al espinazo y llena de bubas y con calenturas continuas».

b) El médico asistiría a la enferma, dándole de comer y «poniendo las medicinas y lo demás necesario que se requiera para curarla».

c) Si la esclava sanare, serviría al médico durante un año y éste cobraría, además, cincuenta pesos. Si muriese, los gastos de enterramiento corrían por cuenta del dueño (44).

La tabla 1 muestra que los índices de morbilidad difieren entre uno y otro grupo, siendo los azucareros los que mayores índices presentan. El número de bozales enfermos es asombrosamente reducido, especialmente si se tiene en cuenta que tradicionalmente se ha asegurado que las tasas de mortalidad durante la travesía eran sumamente elevadas y que los esclavos arribaban en un estado físico deplorable. En los últimos años se ha demostrado, sin embargo, que la proporción de muertes por viaje era sustancialmente menor a lo que se venía afirmando, ya que era interés del propio negrero - es un elemental cálculo económico, aplicable a cual- 
quier mercadería - garantizar que la misma llegara en buenas condiciones (45).

Sin embargo, aun entre los bozales estos índices no pueden considerarse bajos; téngase en cuenta que éste era un grupo poblacional ad hoc, creado exclusivamente con fines comerciales y compuesto únicamente por individuos jóvenes, cuyo estado físico era cuidadosamente revisado por el negrero. Aun así, alrededor del $10 \%$ de los bozales comprendidos entre los quince y diez y nueve años presentaba problemas de salud (figura 3).

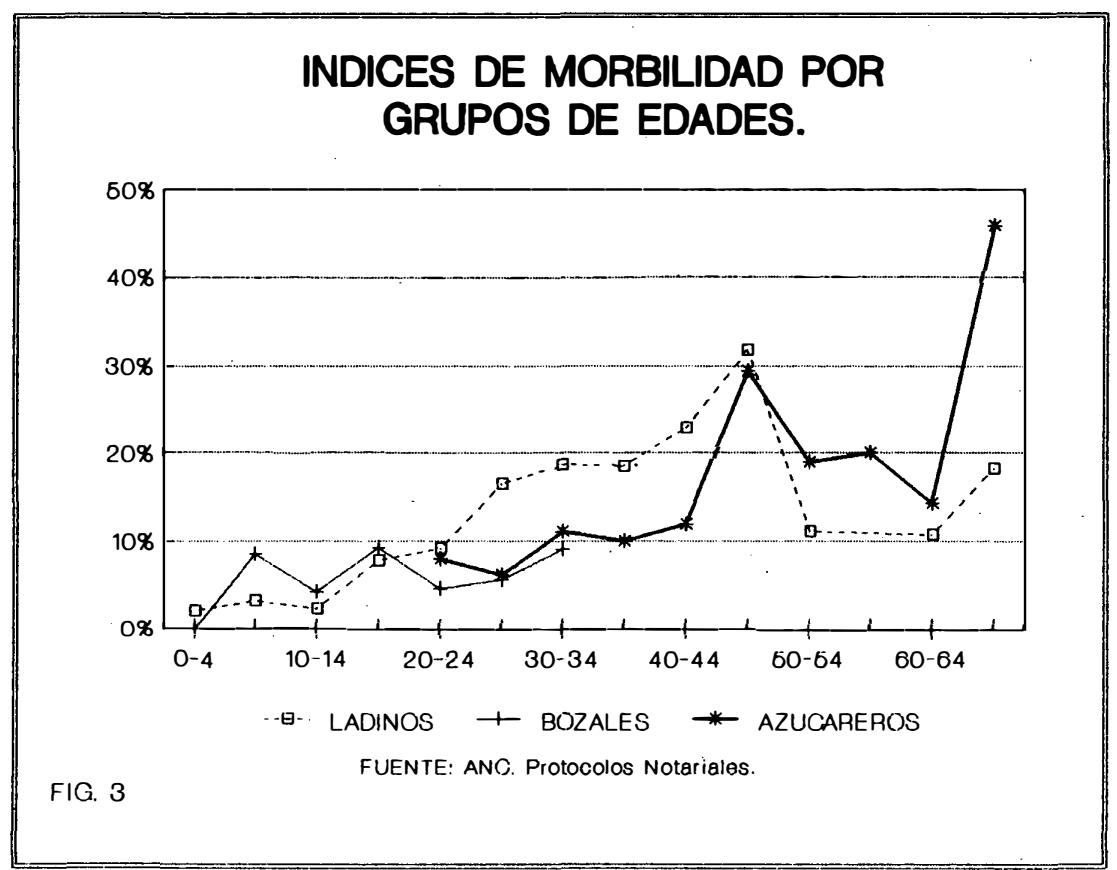

En el caso de los ladinos y azucareros los índices tienden a incrementarse a medida que aumentan las edades y hay grupos etáreos en los que se registra más de una tercera parte de enfermos. Como los datos de los ladinos son extraídos de los contratos de venta, se les puede aplicar el mismo razonamiento realizado en el caso de los bozales, ya que es presumible que como norma los esclavos enfermos no serían llevados al mer- 
cadö. Los altos índices entré los azucareros: indican que a pesàr del carácter artesanal que en la época tenía la producción de azúcar, en estas unidadades el idesgaste físico de los ésclavos era algo mayor; la figura 3 permite observar, no obstante, fla presencia entre los mismos de esclavos con edades relativamente elevadas: (más de sesenta años), por lo que es necesario concluir que dichø dẻsgaste: no és en todo caso comparableal sufrido por lăs 'dotacioneśazucareras dé éṕocas posteriores; ; cuando el desarrollo dè la plantación aźúcarera, abastecedora del mercado mundial; sometió al esclavo a extenuantes niveles de explotación.

Es probable que en esa época los índices de morbilidad fueran, al

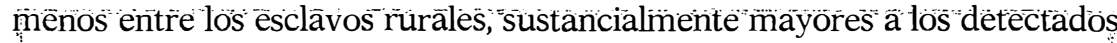
en el período abordado en este trabajo en el que la esclavitud no había ảlcanzado aún su grado máximo de desarrollo. Cuando ello se precise, será posible conocer con mayor détâlle el negativo efecto de la explotación plantacionista en la vida del esclavo y. caracterizar las principales enferịnedades que aquejaban a la población negra de la Isla, lo que cóntribuiría al conocimiento de la historia social de Cuba. El tema, sin embargo, estâ aún sịn estudiar.

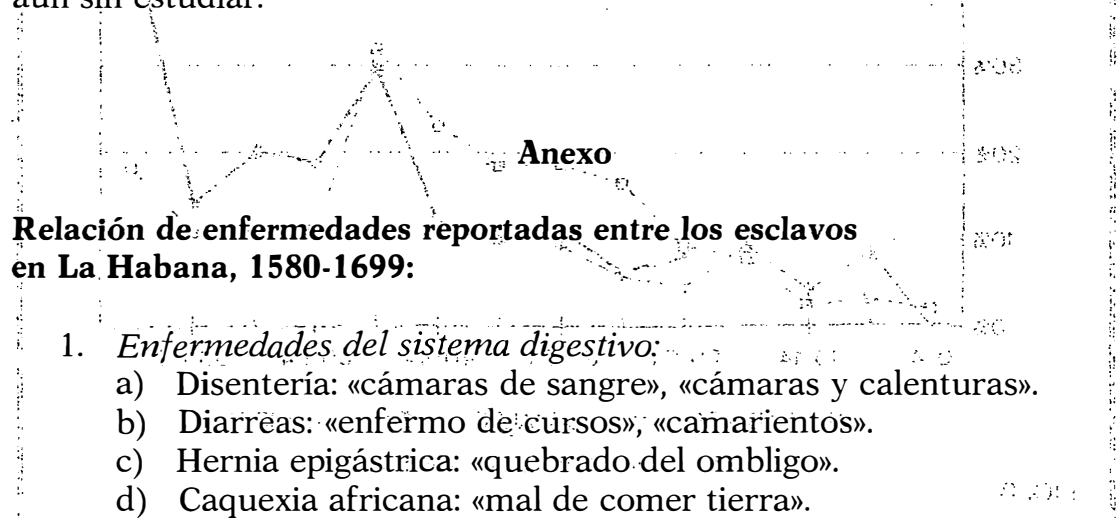

2. Deficiencias nutricionales: "viles y enfermos», «débil y enfermo»,

3. Enfermedades del sistema respiratorio:

a) Neumonía: «dolor de costado».

b) Asma: «ahoguío que le viene a los pechos»; «asmática»:

4. . Tuberculosis: "éticos», "tísicos":

5. Otras enfermedades bacterianas:

a) Lepra: "con indicios de lazarino», «mal de San Lázaro».

b) Tétanos: «tocada de pasmo». 
6. Enfermedades virales:

a) Viruelas.

b) Sarampión.

c) Fiebre amarilla.

7. Enfermedades venéreas:

a) Sífilis: «humor gálico», «morbo gálico», «mal francés».

b) Otras: «bubas», «bubosa», «llena de bubas».

8. Enfermedades del sistema nervioso:

a) Epilepsia: «mal del corazón o gota coral».

b) Ciática: «seático».

9. Trastornos mentales:

a) Síndrome de dependencia alcohólica: «borracho».

b) Otros: "dementado", "espiritado", «endemoniado».

10. Enfermedades del sistema circulatorio:

a) Elefancía (filariasis): "con una pierna regordida», «piernas hin-

b) Hemorroide: "almorranas"

11. Trastornos de la vista:

a) Pobre visión y ceguera: "ciego», «más o menos tuerto de un ojo», «nubes en los ojos», "algo ciego", "principios de nube».

12. Enfermedades de la piel y tejido subcutáneo: «lamparones», «llagas», "clavos de bubas», «fístula», "cáncer», «potra», «empeines», «apostema», «lleno de granos», «lobanillo».

13. Enfermedades del sistema musculoesquelético:

a) Hernias: «quebrado de un compañón» (hernia escrotal), «quebrado de la ingle» (hernia inguinal).

b) Deformidades y defectos: "cojo de una pierna", "achaques en las piernas", "cojo de una pierna de una llaga antigua», "con un dedo de cada mano encogido".

c) Amputaciones: "manco de la mano", "con un dedo cortado", «lisiado del brazo de unos machetazos que le dieron», «manco de un dedo», «manco de dos dedos», "lisiado de un brazo».

14. Fracturas: "quebrado de una pierna», "quebrado y lastimado un brazo", "con una pierna quebrada».

15. Enfermedades de los órganos genitales femeninos:

a) Amenorrea y trastornos menstruales: «que no se le vienen sus 
costumbres», «al comienzo del menstruo le suele dar un dolor de barriga y estar indispuesta».

b) Enfermedades del útero y la vagina: «que se le aboca la madre» (prolapso genital).

16. Enfermedades del oído: «sordo», «sordomudo».

17. Otras enfermedades: "enfermo", «con calenturas continuas», «dolor en la cadera», «le late el corazón».

Fuente: ANC. Protocolos Notariales de La Habana.

Nota: Esta clasificación se ha ajustado, en lo posible, a la International Classification of Diseases. Ninth Revision. Basic Tabulation List with Alphabetical Index. Geneva. World Health Organization. 1978.

\section{NOTAS}

(1) Philip D. Cur tin (1968): «Epidemiology and the Slave Trade». Political Science Quarterly. Vol. 83, n. 2, jun., (p. 190-216); Richard B. Sheridan (1975): «Mortality and the Medical Treatment of Slaves in the British West Indies", en Stanley J. Engerman y Eugene D. Genovese (Eds.): Race and Slavery in the Western Hemisphere: Quantitative Studies. Princeton University Press; Rudolf Hoeprli (1969): Parasitic Diseases in Africa and the Western Hemisphere: Early Documentation and Transmission by Slave Trade. Basel.

(2) Oscar Zanetti (1985): «La historiografía de temática social (1959-1984)». Revista de la Biblioteca Nacional José Martí Enero-abril, n. 1, p. 15.

(3) No se conoce el número exacto de esclavos importados en La Habana durante el período y es por lo tanto difícil determinar qué proporción representa la muestra utilizada; en todo caso, la misma no sería nunca inferior al quince o el veinte por ciento del total.

(4) David Lee Chander (1972): Health and Slavery: a Study of Health Conditions among Negro Slaves in the Viceroyalty of New Granada and its Associated Slave Trade, 1600-1810. Xerox University Microfilms. Michigan, p. 179.

(5) María L. Grande Esteban (1974): El léxico médico del siglo de Oro. Bilbao, p. 12.

(6) Francisco Barrera y Domingo (1953): Reflexiones histórico-físico-naturales-médicoquirúrgicas. Ediciones C.R. La Habana, p. 122.

(7) P. M. Ashburn (1974): The Ranks of Death. A Medical History of the Conquest of America. Cowars-McCann Inc. New York, p. 158.

(8) Willem Pies (Ghilherme Piso) (1948): Historia natural do Brasil Ilustrada. Companhía Editora Nacional. Sao Paulo, p. 33. (Edición original: Amsterdam, 1648).

(9) Agustín Farfán (1944): Tractado breve de medicina. Ediciones Cultura Hispánica. Madrid, fol. 14v. (Edición original: México, 1592).

(10) Ashburn: [7], p. 32.

(11) M. G. Levacher (1847): Guide médical des Antilles et des régions intertropicales. Paris, p. 255 
(12) Gabriel Debien (1974): Les esclaves aux Antilles Françaises (XVIIe-XVIIIe siècles). BasseTerre. Fort-de-France, p. 301.

(13) Jean-Baptiste Labat (1979): Viaje a las Islas de América. Casa de las Américas. La Habana, p. 51.

(14) Honorato Bernard de Chateausalins (1854): El vademecum de los hacendados cubanos. La Habana, p. 143.

(15) Manuel Moreno Fraginals (1978): El ingenio. Complejo económico social cubano del azúcar. Editorial de Ciencias Sociales. La Habana, p. 81.

(16) Gonzalo Aguirre Beltrán (1972): La población negra de México. Estudio etnohistórico. Fondo de Cultura Económica. México, p. 193; Gilberto Freyre (s/f): Casa-Grande y Senzala. Emecé Editores S.A. Buenos Aires, T. I, p. 89.

(17) Octavio de Freitas (1935): Doenças africanas no Brasil. Companhía Editora Nacional. Sao Paulo, p. 50.

(18) Chandler: [4], p. 192.

(19) Diccionario terminológico de Ciencias Médicas (1984). Edición Revolucionaria. La Habana, T. I, p. 154.

(20) JuAn de Cardenas (1945): Problemas y secretos maravillosos de las Indias. Ediciones Cultura Hispánica. Madrid, fol. 197v. (Edición original: México, 1591).

(21) PIES: [8], p. 39.

(22) FARFÁN: [9], fol. 82v.

(23) K. David Patterson y Gerald W. Hartwig (1978): «The Disease Factor: An Introductory Overview», en Gerald W. Hartwig y K. David Patterson (Eds.): Disease in African History. Duke University Press, p. 9.

(24) Archivo General de Indias (AGI). Indiferente General. Leg. 2796. Agradezco esta información al destacado historiador cubano Francisco Pérez Guzmán.

(25) Archivo del Museo de la ciudad de La Habana. Actas Capitulares del Ayuntamiento de La Habana. Trasuntadas (ACAHT). Vol. 1667-1672, fol. 462v.

(26) FARFÁN: [9], fol. 48v.

(27) José A. MARTínez Fortún Foyo (1952): «Epidemiología (síntesis cronológica)». Cuadernos de Historia Sanitaria. La Habana, p. 28-29.

(28) Archivo Nacional de Cuba (ANC). Protocolos Notariales de La Habana. Escribanía Regueyra. 1604, fol. 520.

(29) Ibidem. Escribanía Fornari. 1694, fol. 294v.

(30) Actas Capitulares del Ayuntamiento de La Habana, 1550-1578. Municipio de La Habana. 1937-1946. T. II, p. 304; ACAHT. Vol. 1672-1683, fol. 26v.

(31) ANC. Protocolos Notariales de La Habana. Escribanía Regueyra. 1589, fol. 819v.

(32) DeBIEN: [12], p. 316.

(33) FARFÁN: [9], fol. 302.

(34) JuAN SORAPAN DE RiERos (1616): Medicina española contenida en proverbios vulgares de nuestra lengua. Granada, p. 99

(35) PIES: [8], p. 21.

(36) FARFÁN: [9], fol. 302

(37) Alonso de Chirino (1973): Menor daño de la medicina. Edición crítica y glosario de

María Teresa Herrera. Universidad de Salamanca, p. 211. (Edición original: Sevilla, 1506).

(38) Farfán: [9], fol. 33v.

(39) ChandLeR: [4], p. 205

(40) PIES: [8], p. 37.

(41) ANC. Protocolos Notariales de La Habana. Escribanía Fornari. 1671, fol. 760.

Asclepio-II-1991 
(42) Sobre esta denominación, véase Chirino: [37], p. 194.

(43) ANC. Protocolos Notariales de La Habana. Escribanía Regueyra. 1604, Libro 7, fol. $40 \mathrm{v}$.

(44) Ibidem. Escribanía Fornari. 1640, fol. 692.

(45) A principios del siglo XVII (1605-1621), por ejemplo, VILA VILAR (1977): Hispanoamérica y el comercio de esclavos. Sevilla, p. 130, ha encontrado en un total de 29 buques una mortalidad media del 23\%, aunque los valores sufren bruscas variaciones de un embarque a otro y en algunos no se reportan bajas durante la travesía. A fines del propio siglo y principios de la centuria siguiente (1680-1725), alrededor del $12 \%$ de los esclavos transportados por la Royal African Company fallecían en el viaje, según afirmación de DAVID W. GaLENSON (1986): Traders, Planters and Slaves. Market Behavior in Early English America. Cambridge, p. 38. En el siglo XVIII, los excelentes estudios de Herbert KıeIN (1978): The Middle Passage; Comparative Studies in the Atlantic Slave Trade. Princeton, p. 65, 85, 199, arrojan una mortalidad media de alrededor de un 10\% y en el período 1766-1771 GLORIA GarCí (1986): «El mercado de fuerza de trabajo en Cuba: el comercio esclavista (1760-1789)», en La esclavitud en Cuba. La Habana, p. 138, reporta únicamente un $1.4 \%$ de muertes entre los esclavos introducidos en La Habana. 